\title{
Left mainstem bronchial rupture during one-lung ventilation with Robertshaw double lumen endobronchial tube
} -A case report-

\author{
Hyun Kyu Kim ${ }^{1}$, Joo Hwan Jun ${ }^{1}$, Hee Sung Lee ${ }^{2}$, Young Ryong Choi ${ }^{1}$, and Mi Hwa Chung ${ }^{1}$ \\ Departments of ${ }^{1}$ Anesthesiology and Pain Medicine, ${ }^{2}$ Thoracic and Cardiovascular Surgery, Kangnam Sacred Heart Hospital, Hallym \\ University College of Medicine, Seoul, Korea
}

Lung separation using a double-lumen endobronchial tube is necessary for video assisted thoracoscopy (VATs). Bronchial rupture after intubation with a double-lumen endobronchial tube has been rarely reported. We report a case of a 70-year-old man who had solitary pulmonary nodule in his right upper lobe. He was intubated with a leftsided Robertshaw double-lumen endobronchial tube. He underwent a VATs right upper lobectomy with the one-lung ventilation of left lung. During the operation, the rupture of the left mainstem bronchus was detected. Immediately, the thoracotomy was performed and the ruptured left mainstem bronchus was repaired with absorbable sutures (vicryl). Seven days later he had a bronchoscopy to examine the left mainstem bronchus. There was no evidence of the bleeding, leakage and inflammation. Subsequent course was uneventful. Tracheobronchial injuries related to the double-lumen endobronchial tube are discussed. (Korean J Anesthesiol 2010; 59: S21-S25)

Key Words: Bronchial rupture, Complication, Double lumen endobronchial tube, Intubation.

Starting from several years ago, operations using Video-assisted thoracoscopy (VATs) has been increasing. For operations with VATs, one lung ventilation through lung separation is essential. The most widely used instrument for lung separation is a double-lumen endobronchial tube [1]. The tracheobronchial rupture during intubation with a double-lumen endobronchial tube is a rare complication [2,3]; although experienced anesthesiologists take charge of intubation, managing the double-lumen endobronchial tube, tracheobronchial injuries are still reported [4].
The risk factors of tracheobronchial injury include unskilled operators, improper usage of the stylet, an immoderate number of attempts of intubation, tracheobronchial malformation, overexpansion of high pressure-low capacity cuff, and advanced age $[2,3,5,6]$.

Authors detected a rupture of the left mainstem bronchus with the length of $1.5 \mathrm{~cm}$ during one lung ventilation with a double lumen endobronchial tube, and the thoracotomy was immediately performed so that the ruptured left mainstem bronchus was repaired completely. The paper reports the case

Received: March 10, 2010. Revised: 1st, March 24, 2010; 2nd, April 2, 2010. Accepted: April 13, 2010.

Corresponding author: Mi Hwa Chung, M.D., Department of Anesthesiology and Pain Medicine, Kangnam Sacred Heart Hospital, Hallym University College of Medicine, 948-1, Daerim 1-dong, Yeongdeungpo-gu, Seoul 150-071, Korea. Tel: 82-2-829-5226, Fax: 82-2-845-1571, E-mail: mhchung20@hallym.or.kr

(c) This is an open-access article distributed under the terms of the Creative Commons Attribution Non-Commercial License (http:// creativecommons.org/licenses/by-nc/3.0/), which permits unrestricted non-commercial use, distribution, and reproduction in any medium, provided the original work is properly cited. 
with the reference on the subject.

\section{Case Report}

We report a case of a 70-year-old male patient with a height of $170 \mathrm{~cm}$ and a weight of $66 \mathrm{~kg}$ taking allopurinol $100 \mathrm{mg}$ three times a day after being diagnosed gout 20 years ago. Four years ago, he underwent total parotidectomy under general anesthesia for adenocarcinoma of the right parotid gland and received radiation therapy. During the tracing survey of his adenocarcinoma of the right parotid gland, a $1.5 \times 1 \mathrm{~cm}$ solitary pulmonary nodule in his right upper lobe was detected from positron emission tomography performed 8 months ago, and the size was gradually increasing. A right upper lobectomy was planned depending on the results of the biopsy and frozen section with VATs.

Vital signs at the time of hospitalization were within normal range, and there was no special opinion about the patient except the increased level of creatinine at $2.11 \mathrm{mg} / \mathrm{dl}$ from the preoperative evaluation. For premedication, $0.2 \mathrm{mg}$ of glycopyrrolate was injected intramuscularly 30 minutes before the surgery. Vital signs at the time of arrival at the operation room were blood pressure at $178 / 110 \mathrm{mmHg}$, heart rate at 77 beats $/ \mathrm{min}$, and body temperature at $35.9^{\circ} \mathrm{C}$. For the induction of anesthesia, while $300 \mathrm{mcg} / \mathrm{hr}$ of remifentanil was infused, $2 \mathrm{mg} / \mathrm{kg}$ of propofol and $0.6 \mathrm{mg} / \mathrm{kg}$ of rocuronium were also injected. Then a left 37 French Robertshaw double lumen endobronchial tube (Broncho-Cath Left, Mallinckrodt Medical, Ireland) was intubated with a stylet. After the tip of the tube passed the vocal cords, the stylet was removed; and after the tracheal cuff passed the vocal cords, the tube was advanced by rotating it at a 90 degree angle counterclockwise. When the tube was inserted at a depth of $29 \mathrm{~cm}$ to lips, resistance was felt. The resistance indicated that the tube is at the left mainstem bronchus, so that the tracheal cuff and the bronchial cuff were inflated with $6 \mathrm{ml}$ and $2 \mathrm{ml}$ of air, respectively. After making a judgment that the location of tube is appropriate by auscultation without using bronchoscope, the bronchial cuff was deflated in order to prevent bronchial injury from postural changes. After that, it was confirmed that there was no problem with the location of the tube by auscultation after the posture of the patient was changed to the left lateral decubitus position and the bronchial cuff was inflated with $2 \mathrm{ml}$ of air. Anesthesia was maintained with isoflurane 1.2 vol\%-oxygen $2 \mathrm{~L} / \mathrm{min}$ air $2 \mathrm{~L} / \mathrm{min}$ and remifentanil $250 \mathrm{mcg} / \mathrm{hr}$ were continuously infused intravenously. The results of the arterial blood gas analysis (ABGA) right after the anesthesia induction was $\mathrm{pH}$ 7.34, $\mathrm{PaCO}_{2} 41 \mathrm{mmHg}$, and $\mathrm{PaO}_{2} 279 \mathrm{mmHg}\left(\mathrm{FiO}_{2}\right.$ 0.5) during bilateral lung ventilation; the results from ABGA one hour after the beginning of the operation was $\mathrm{pH} 7.33, \mathrm{PaCO}_{2} 41 \mathrm{mmHg}$,
$\mathrm{PaO}_{2} 236 \mathrm{mmHg}\left(\mathrm{FiO}_{2}\right.$ 0.5).

After 170 minutes from the beginning of VATs operation, the airway pressure suddenly increased to $40 \mathrm{cmH}_{2} \mathrm{O}$ and the capnogram was not detected. At that moment, the patient's muscle relaxation was enough and self-respiration was not detected. Immediately, manual ventilation was performed but upon the auscultation, ventilation was not detected. The depth of the tube was $26 \mathrm{~cm}$ to lips, shifted a bit from the beginning, so after removing all air in the cuff, the tube was advanced again to the depth of $29 \mathrm{~cm}$ while the tracheal cuff was inflated by $6 \mathrm{ml}$ of air. Until then, the saturation of pulse oximeter was maintained at $99 \%$. Due to no ventilation, it was decided to check the location of the tube with a bronchoscope after identifying ventilation first. As the result of auscultation during the manual ventilation, breathing sounds from both sides of the chest were detected and the expansion of lungs could be seen by thoracoscope. After expanding the bronchial cuff with $2 \mathrm{ml}$ of air, breathing sounds from both sides of the chest were still detected. The left one-lung ventilation was attempted by clamping the tracheal tube with forceps, but while the expansion of the right lung was detected on the screen with the thoracoscope, breathing sounds from the left side were not detected. After removing the forceps from the tracheal tube and clamping the bronchial tube with the forceps, the left onelung ventilation was detected. It was concluded that the tube is located at the right side of the bronchus, so we monitored by inserting a fiberoptic bronchoscope into the tracheal tube. It was detected that the tube is located in the right bronchus, so after removing the air of all cuff, the tube was pulled off up to the depth of $24 \mathrm{~cm}$. Although the tube was advanced through the use of the bronchoscope, the tube kept falling into the right bronchus. We made two more attempts but the results were the same. Therefore we put the bronchoscope into the left mainstem bronchus through the bronchial tube. The tube was advanced using the bronchoscope as a guide-wire to the depth of $29 \mathrm{~cm}$. Although there was a sense of resistance at $27 \mathrm{~cm}$, we considered that it was from the friction caused by the bronchoscope. As a result of monitoring the tracheal tube with the bronchoscope, the tube located in the left mainstem bronchus was detected to be at the proper depth. After that, the left one-lung ventilation developed normally.

The operation was performed again, and when sampling the lymph nodes of the subcarinal region after finishing right upper lobectomy, an air bubble coming from the direction of the left mainstem bronchus was detected. When dissecting tissue to the direction of the air bubble, the amount of air leakage increased. Then the appropriate lung ventilation was not performed and the saturation of pulse oximeter was decreased to $89 \%$. We transited to the bilateral lung ventilation immediately, and after starting the manual ventilation by inhaling $100 \%$ oxygen, the 
saturation was maintained at $99 \%$. After removing all the air inside the cuff and pulling the tube out by $6 \mathrm{~cm}$, the tracheal cuff was inflated by $6 \mathrm{ml}$ of air. The carinal region and the left and the right bronchus were examined with a fiberoptic bronchoscope, and the linear rupture in the traveling direction from the left mainstem bronchus was detected. As the result of monitoring from immediate thoracotomy, the rupture with the length of $1.5 \mathrm{~cm}$ was detected from the posteromedial surface of the left mainstem bronchus just below carina (Fig. 1). The simple primary suture was done on the rupture region with vicryl, and there was no more air leakage after finishing the repair (Fig. 2).

After finishing the operation, the tube was extubated in the operation room, and the patient was monitored for a day in the

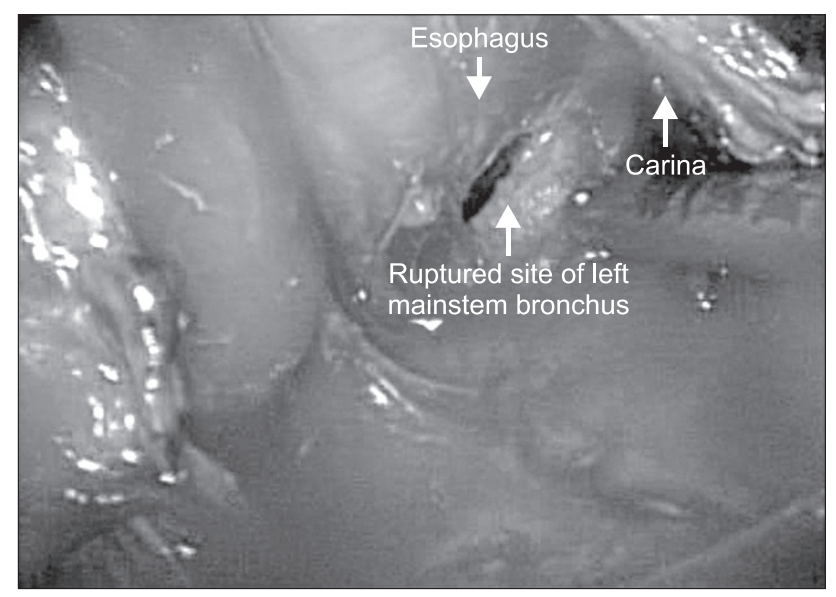

Fig. 1. The ruptured site of the left mainstem bronchus is marked with an arrow. We detected massive air leakage from the ruptured site during positive pressure ventilation. The carina and esophagus are also shown.

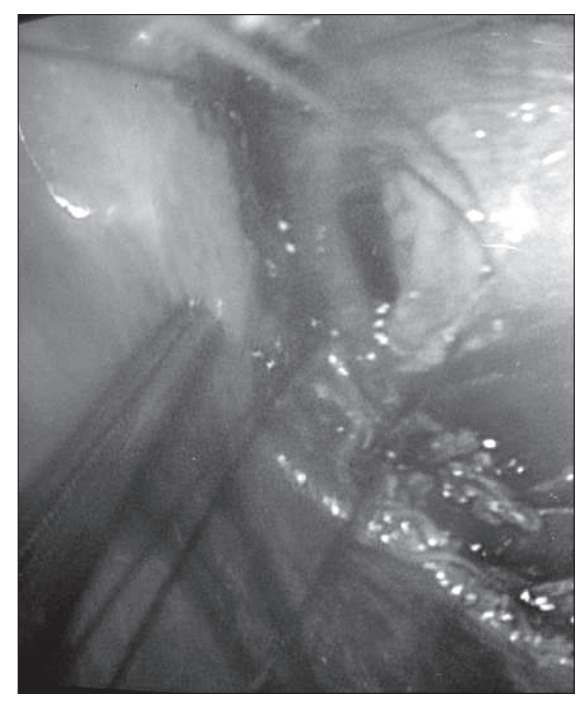

Fig. 2. The ruptured left mainstem bronchus is repaired with absorbable sutures (vicryl). intensive care unit. On the next day, the patient was moved to general ward. From the bronchoscope examination conducted 7 days after the operation, a linear laceration from the upper left mainstem was detected, indicating that the patient was recovering well (Fig. 3). Nine days after the operation, the patient left the hospital after making a full recovery.

\section{Discussion}

The tracheobronchial system injury is a rare complication but it can lead to fatal outcomes. Recently, there are increasing cases of intubation, tracheostomy, and bronchoscope causing injury rather than thoracic trauma [7]. Lampl [8] had researched 27 patients with tracheobronchial system injuries from 1986 to 2001 and among them, 8 patients suffered bronchial injury while 2 of them had injuries from tubes, all from double-lumen endobronchial tubes. Hofmann et al. [7] investigated 19 patients with iatrogenic tracheobronchial system rupture; fifteen of them had ruptures caused by single lumen endotracheal tubes and the remaining 4 from double lumen endobronchial tubes.

When using a double lumen endobronchial tube, the right bronchial has the most frequent tracheobronchial system rupture. Meanwhile, since the left bronchial stretches elatively long inside the mediastinum, it is layered with a lot of peribronchial tissue. Accordingly, in case of the left bronchial rupture, the diagnosis takes 30 days on average [9].

Causes for the rupture during intubation can be classified into two categories: the technological and the anatomic cause. For the technological cause, the maintenance of intubation,

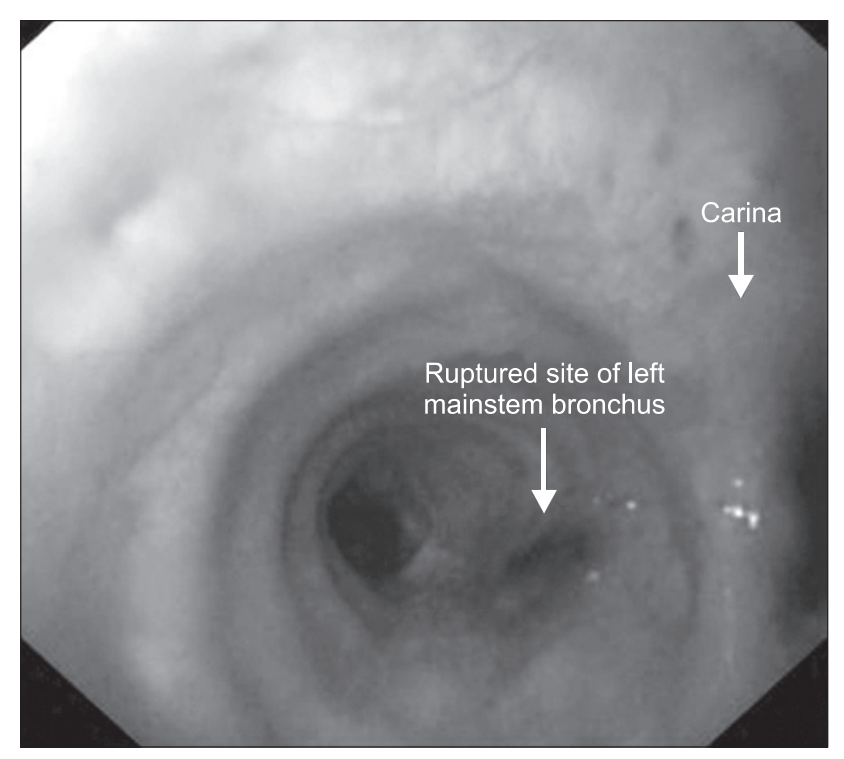

Fig. 3. The healing process of the left mainstem bronchus is shown on the bronchoscopic finding. There is no bleeding, leakage and inflammation at the suture site. 
unskilled anesthesiologists, improper usage of stylets, overinflation of cuffs, rupture of cuffs, no pressure reduction of cuffs during posture changes are included. Anatomic causes include congenital malformation of airway, tracheobronchial transformation due to the lymphatic gland or tumor, inflammatory lesions, chronic obstructive bronchial diseases [10]. This is frequent especially for females because it is easy for the bronchus to be ruptured when the depth and size of the tubes are not appropriate due to a smaller trachea in women who are relatively shorter compared to men. The usage of tubes of an improper size is one of the major causes for urgent accidents as well as emergency intubation [7]. Also iatrogenic tracheobronchial rupture may occur in the absence of common risk factors such as difficult intubation, use of a stylet, and cuff overinflation. The exact mechanisms are uncertain, but the direct laceration from the tip of the endotracheal tube to the flaccid posterior tracheal membrane during advancing the tube is the most possible mechanism [11].

In this case, Robertshaw double lumen endobronchial tube was used for right upper lobectomy, and since the tube was shifted during the operation, it was intubated again with a bronchoscope. While tracing causes for a detected air bubble from the left lung around the end of operation, the rupture in stretching direction of the bronchus from left mainstem bronchus was detected. The part is a borderline of tracheal cartilage and membrane, and the cause of the rupture from the tip of the tube or cuff can be suspected. Kim et al. [3], Shin et al. [6] have reported that the left mainstem bronchial rupture was due to the cuff overinflation during the intubation of a double lumen endobronchial tube. Unlike their cases, the cause of rupture in this case was suspected that the direct rupture from repeated intubation without using the bronchoscope to identify the correct position of endobronchial tube. However, considering that there was no other option but to change the location of the tube because of the urgent risk of impossible ventilation. It was also difficult to manipulate the lung due to weak lung tissue and bronchus. The advanced age of the patient also adds to the risk of bronchial rupture because tissue is weaker than the tissue of a young adult patient.

Clinical symptoms include mediastinal emphysema, subcutaneous emphysema, and bleeding and immediately present after starting mechanical ventilation or intubation. Pneumothorax is a relatively rare case but if it occurs, it is communicated with pleural cavity. There are also some cases where the symptoms are not detected for a long time [7].

The bronchial rupture was not detected immediately after the intubation in this case. The size of rupture was $1.5 \mathrm{~cm}$, which is not very big. Also since it was the left mainstem bronchus, which is surrounded by peripheral tissues, the air leakage was not detected before sampling the subcarinal lymph nodes when the rupture was opened by dissecting surrounding tissues.

The diagnosis can be done with a radiology examination, but the most accurate method is to use a bronchoschope $[7,9]$. The treatment method can be decided through examining the location and range of rupture with a bronchoscope [7]. Mild symptoms and small size ruptures can be treated with conservative treatment [7]. For surgical treatment, the rupture should be sutured, the merits being effective ventilation from the suturing of the ruptured part, the short recovery period of the ruptured part, and the prevention of mediastinitis as well as tracheal stenosis [11]. So surgical treatment should be considered first.

In order to prevent tracheobronchial injury during intubation, first, avoid immoderate power during intubation. Second, select a stylet of a proper size. Third, verify if the tube is the best fit for the location during intubation or when the patient needs to change postures using a bronchoscope. Fourth, inflate the tracheal cuff within 5-6 ml and the bronchial cuff within $2-3$ $\mathrm{ml}$. Fifth, recheck the location when there is a need for more inflation than 5-6 $\mathrm{ml}$ for the tracheal cuff and $2-3 \mathrm{ml}$ for the bronchial cuff. Sixth, use a tube with the biggest possible caliber in order to seal the airway only with a small amount of air. Seventh, deflate the bronchial cuff during changing postures. Eighth, maintain the pressure under $30 \mathrm{cmH}_{2} \mathrm{O}$ by continuously monitoring the cuff pressure during the use of nitrous oxide. Ninth, for esophageal resection, especially for dissecting the membranous trachea and cervical esophagus, beware of deflating the tracheal cuff [2].

The patient from this case fully recovered without special problems because the bronchial rupture was immediately repaired after being detected during the operation. However, the delayed detection of the bronchial rupture can lead to fatal complications including mediastinitis, pneumothorax, and subcutaneous emphysema. In particular as mentioned earlier, it is highly possible to detect the left mainstem bronchus rupture too late, so if it is not detected during the operation, reoperation is unavoidable and the prognosis of the patient would be extremely bad. Accordingly, for operations using a double lumen endobronchial tube, medical experts should be excessively careful with intubation and its management in order to avoid a tracheabronchial injury. They must carefully observe the progress of patients after the operation, and if there are suspicious symptoms, adequate diagnosis and quick treatment should be done considering the possibility of a tracheabronchial injury.

\section{References}

1. Steven MN, James BE, Edmond C. Anesthesia for thoracic surgery. In: Clinical anesthesia. 6th ed. Edited by Barash PG, Cullen BF, 
Stoelting RK, Cahalan MK, Stock MC: Wolters Kluwer, Lippincott Williams\& Wilkins. 2009, pp 1042-3.

2. Kim BJ, Kim JW, Shin DY, Hong KH. Tracheal rupture during the use of robertshaw double-lumen endobronchial tube for one-lung ventilation. Korean J Anesthesiol 1997; 32: 131-4.

3. Kim KI, Chee HK, Kim HS, Lee HS, Lee WY. Left bronchial rupture following endobronchial intubation. Korean J Thorac Cardiovasc Surg 1998; 31: 1014-6.

4. Yüceyar L, Kaynak K, Cantürk E, Aykaç B. Bronchial rupture with a left-sided polyvinylchloride double-lumen tube. Acta Anaesthesiol Scand 2003; 47: 622-5.

5. Lim HK, Chae YJ, Im KB, Kim SY, Yoon KB. Tracheal rupture following insertion of double-lumen endobronchial tube during bronchoesophageal fistular repair. Korean J Anesthesiol 1999; 37: 527-9.

6. Shin YD, Bae JH, Kim ST, Lim SW, Hong JS, Lee SJ, et al. Tracheobronchial rupture during double-lumen endobronchial tube insertion for one-lung ventilation: 2 cases. Korean J Anesthesiol 1999; 37: 1149-52.

7. Hofmann HS, Rettig G, Radke J, Neef H, Silber RE. Iatrogenic ruptures of the tracheobronchial tree. Eur J Cardiothorac Surg 2002; 21: 649-52.

8. Lampl L. Tracheobronchial injuries. Conservative treatment. Interact Cardiovasc Thorac Surg 2004; 3: 401-5.

9. Jamal-Eddine H, Ayed AK, Peric M, Chandrasekaran C, Al-Sarraf N. Complex bronchial ruptures successfully treated with primary reconstruction and limited lung resection. Gen Thorac Cardiovasc Surg 2009; 57: 261-3.

10. Hasan A, Low DE, Ganado AL, Norton R, Watson DC. Tracheal rupture with disposable polyvinylchloride double-lumen endotracheal tubes. J Cardiothorac Vasc Anesth 1992; 6: 208-11.

11. Conti M, Pougeoise M, Wurtz A, Porte H, Fourrier F, Ramon P, et al. Management of postintubation tracheobronchial ruptures. Chest 2006; 130: 412-8. 